\title{
A ORGANIZAÇÃO DA BIBLIOTECA DA ESCOLA NORMAL DE CAMPINAS - O MAPEAMENTO DAS COLEÇÕES PEDAGÓGICAS (1930-1960) NOS APONTAMENTOS DE UMA PESQUISA
}

\author{
Maria Cristina Menezes \\ CIVILIS/FE/UNICAMP \\ menezes.mariacristina@gmail.com \\ Maria de Lourdes Pinheiro \\ CIVILIS/FE/UNICAMP \\ pinheiro.lou@gmail.com
}

\begin{abstract}
RESUMO
A presente discussão articula-se ao projeto "Patrimônio Histórico Educativo: a organização da Biblioteca da Escola Normal de Campinas" e vincula-se às ações desenvolvidas nos projetos do CIVILIS (Grupo de Estudos e Pesquisas em História da Educação, Cultura Escolar e Cidadania), da Faculdade de Educação da UNICAMP, sob a coordenação da Profa. Dra. Maria Cristina Menezes. A discussão parte de uma proposta de pesquisa que tem como objetivo fazer o levantamento das coleções pedagógicas da biblioteca da antiga Escola Normal de Campinas. Os títulos foram organizados por coleções e a pesquisa busca procedimentos de identificação e descrição dos itens. A organização desses espaços, por consequência, é uma importante contribuição para a preservação do patrimônio históricoeducativo.
\end{abstract}

Palavras-chave: Manuais Escolares. Formação de professores. Patrimônio HistóricoEducativo.

\section{THE ORGANIZATION OF THE NORMAL SCHOOL LIBRERY OF CAMPINAS - THE MAPPING OF PEDAGOGICAL COLLECTIONS (1930-1960) IN THE APPOINTMENTS OF A RESEARCH}

\begin{abstract}
This argument is articulated to the project "Historical and Educational Heritage: the organization of the Normal School Librery of Campinas" and is linked to the actions developed by the projects of CIVILIS (Group of Studies and Researches in History of Education, School Culture and Citizenship), of the Faculty of Education of UNICAMP, under the coordination of Prof. Dr. Maria Cristina Menezes. The discussion starts from a research proposal that aims to survey the pedagogical collections of the Library of the former Normal School of Campinas. The titles were organized by collections and the research seeks to identification procedures and items description. The organization of these spaces, therefore, is an important contribution to the preservation of the historical and educational heritage.
\end{abstract}

Keywords: School textbooks. Teacher training. Historical and Educational Heritage. 


\section{INTRODUÇÃO}

A presente discussão articula-se ao projeto "Patrimônio Histórico Educativo: a organização da Biblioteca da Escola Normal de Campinas" e vincula-se às ações desenvolvidas nos projetos do CIVILIS (Grupo de Estudos e Pesquisas em História da Educação, Cultura Escolar e Cidadania), da Faculdade de Educação da UNICAMP, sob a coordenação da Profa. Dra. Maria Cristina Menezes, com o auxílio de bolsistas do Ensino Médio, alunos das próprias escolas, pelo PIBIC-EM/CNPq, além de graduandos e pósgraduandos da UNICAMP.

A discussão parte de uma proposta de pesquisa que tem como objetivo fazer o levantamento das coleções pedagógicas da biblioteca da antiga Escola Normal de Campinas, atual EE Carlos Gomes de Campinas/SP. Assim, para este estudo, os títulos foram organizados por coleções e vem sendo realizada a identificação e a descrição dos mesmos. A descrição dos livros em fichas forjadas a partir de um código de referência que adere ao já descrito para documentos e outros itens dos diferentes acervos deste arquivo, por constituírem-se em itens de um mesmo fundo arquivístico, traz as marcas que os identificam ao fundo e ao mesmo tempo as particularidades da descrição de um item bibliográfico.

O levantamento e o estudo das coleções pedagógicas também possibilitam compreender como os saberes pedagógicos conquistaram espaços no campo educacional em conformação, no período delimitado para esse estudo. Dessa forma, a partir dos anos iniciais da década de 1930 acentuavam-se os embates educacionais entre os educadores denominados como os "pioneiros da educação nova" e aqueles educadores denominados como católicos, por pertencerem a grupo defensor das ideias católicas. Tais grupos se utilizaram, sobretudo, do impresso como um dispositivo estratégico para divulgar ou censurar concepções pedagógicas com a intenção de consolidar um determinado modelo escolar ${ }^{1}$. Ao final da década de 1960, contudo, o movimento renovador no Brasil mostrava um esgotamento.

\footnotetext{
${ }^{1}$ Os "pioneiros" publicaram, por exemplo, a coleção "Biblioteca de Educação", organizada por Lourenço Filho, a partir de 1927, e a coleção "Biblioteca Pedagógica Brasileira", com início em 1931, na qual a série "Atualidades Pedagógicas" recebeu a organização de Fernando de Azevedo, num primeiro momento e, posteriormente, de João Batista Damasco Penna. Os "católicos”, por sua vez, publicaram coleções como "Curso de Psicologia e Pedagogia", a partir de 1946, com organização do professor Theobaldo de Miranda Santos, e "Biblioteca Didática Brasileira", série "Escola Viva", a partir de 1949, com direção do professor Afro do Amaral Fontoura.
} 


\section{LEVANTAMENTO E ESTUDO DE COLEÇÕES}

O levantamento e o estudo das coleções pedagógicas, nesta biblioteca específica, possibilitam conhecer a organização que um dia receberam pela bibliotecária que a escola manteve por aproximadamente quarenta anos, uma vez que os livros que compõem as coleções presentes nesta biblioteca trazem marcas como carimbos, classificação, além de marcas de posse e marginalias, e número de registro (tombo). Como observa Menezes (2011, p. 2):

[...] A guarda do acervo, a organização e a manutenção estão fortemente articulados aos propósitos educacionais de um período e dos profissionais que então compunham o quadro funcional da instituição, tal como a figura do bibliotecário, nesta escola uma bibliotecária, que permaneciam por muitos anos na escola e tinham, portanto, um conhecimento aprofundado, podendo-se dizer, muito íntimo do seu setor, como no caso específico do acervo bibliográfico.

Os livros trazem ainda uma ficha de registro de empréstimo, com as datas de retirada e devolução pelos usuários que os consultavam, o que pode dar alguma pista, ainda que superficial, sobre a demanda, se significativa (ou não) de empréstimos e quais os títulos mais procurados. Para além, é possível uma análise das "marcas de leitura" muitas vezes deixadas nos livros por aqueles que os tomavam de empréstimo, "que podem ser lidas como indícios da presença constante do leitor" (CUNHA, 2012, p. 25). O estudo de tais marcas traz a possibilidade de se compreender como se deu a circulação dessas coleções entre professores da instituição e alunos do curso normal e o uso provável que delas fizeram.

Os livros possuem também fichas matrizes com informações de cada obra, por meio das quais será possível saber quantos exemplares havia de cada livro, se as coleções estavam completas ou se havia somente os exemplares atualmente localizados. De acordo com Menezes (2011, p. 4):

[...]A ficha matriz, neste caso, é uma ficha para controle da bibliotecária, nela as informações são bem completas sobre cada obra, no trabalho de organização do acervo da instituição. Essas fichas, durante os trabalhos de organização do arquivo histórico da instituição, foram consideradas como documento histórico. As fichas matrizes eram desdobradas para, a partir das informações que continham, poder se organizar as fichas que iriam ser consultadas pelos consulentes. [...]

A preocupação com o levantamento das coleções pedagógicas no período delimitado não se reduz, porém, como salienta Fernandes $(2009$, p. 2), “[...] à etiquetagem dos achados ou ao recenseamento dos escritos, mas sim à indagação da razão dos acontecimentos passados, das ideias construídas, dos sonhos sonhados". Neste sentido, esta proposta fundamenta-se em uma abordagem cultural da história, sobretudo a partir das premissas de 
Chartier (1990), para quem é necessário considerar o impresso em sua materialidade de objeto cultural, preocupando-se com as práticas que o produziram e os usos que dele são feitos, o que significa discernir as marcas de sua produção, circulação e usos. Em função disso, os impressos com destinação pedagógica também devem ser vistos como estratégias editoriais que apresentavam determinados saberes compreendidos como necessários à prática docente.

O conceito de estratégia é tomado de Certeau (1996), para quem o exercício das práticas pressupõe um lugar de poder que o espaço das estratégias é capaz de produzir, mapear e impor. Daí a necessidade de considerar a materialidade do livro e de analisar como estratégias seus dispositivos textuais e editoriais para a formação e a prática de professores. É nesse sentido que se deve interrogar como os impressos pedagógicos organizaram e constituíram uma cultura pedagógica considerada como necessária para a formação e a prática dos professores, quem selecionava os saberes pedagógicos veiculados pelos mesmos e qual a configuração material (textual e tipográfica) utilizada.

Os estudos sobre os impressos são relevantes, sobretudo, por revelar as transformações culturais e políticas que emergiam no momento da sua publicação, bem como as propostas pedagógicas que balizavam a formação de professores, a estrutura da escola e as políticas educacionais. A organização desses espaços, por consequência, é uma importante contribuição para a preservação do patrimônio histórico-educativo.

\section{A BIBLIOTECA HISTÓRICA PRESERVADA EM SUA MATERIALIDADE}

Um importante campo de investigação para a história da educação tem se consolidado a partir de estudos sobre impressos pedagógicos e seus usos escolares. Tais estudos têm colocado ênfase nos suportes materiais da produção, circulação e apropriação dos saberes pedagógicos, abrangendo desde pesquisas sobre livros de uso escolar, imprensa periódica especializada em educação, bibliotecas escolares e coleções dirigidas a professores.

Para Biccas e Carvalho (2000), a materialidade desses objetos passa a ser o suporte do questionário que orienta o investigador no estudo das práticas formalizadas nos seus usos. Conforme as autoras, a ênfase em tais usos tem deslocado o olhar do historiador da educação dos modelos pedagógicos para a multiplicidade dos dispositivos materiais em que se inscrevem, como produtos culturais determinados, e para as práticas diferenciadas de sua apropriação.

Nesse sentido, o projeto ora em estudo ao mesmo tempo em que possibilita o levantamento das coleções pedagógicas, buscando compreender "as razões e os efeitos dessas 
materialidades" (CHARTIER, 1999, p. 35), realiza também a organização do material com vistas à sua preservação. Conforme Catani e Souza (2001, p. 241), "a realização de pesquisas que possam vir a contribuir para localizar e sistematizar dados ou informações constitui tarefa fundamental para a superação das limitações com que se lida, no Brasil, no tocante ao acesso e à conservação das fontes".

Em vista disso, o projeto de organização dos acervos históricos que compõem o Arquivo histórico documental da Escola Normal de Campinas, no qual se inclui a Biblioteca Histórica, não circulante da mesma, vem sendo realizado desde 2001, quando primeiramente a equipe de pesquisadores deteve-se sobre o acervo dos documentos manuscritos e iconográficos. Em 2003 no Centenário da Instituição foi possível organizar uma exposição documental, desses itens, manuscritos e iconográficos, que naquele momento já se encontravam em bom estado de preservação e em fase de descrição, após a ação da equipe de investigadores. Os manuais ganharam luz, literalmente, uma vez que se encontravam depositados dentre as câmaras escuras dos porões da instituição, nas quais permaneceram por largo período. Até o presente momento foi realizado o levantamento de vinte e cinco coleções pedagógicas nesta biblioteca, que abrangem o período 1930-1960, conforme o quadro abaixo:

Quadro 1: Coleções Pedagógicas (1930-1960) - EE Carlos Gomes.

\begin{tabular}{|c|c|c|}
\hline Coleção & Editora & Organização e/ou Direção \\
\hline Biblioteca de Educação & $\begin{array}{l}\text { Companhia } \\
\text { Melhoramentos/SP }\end{array}$ & $\begin{array}{l}\text { Manoel Bergström Lourenço } \\
\text { Filho }\end{array}$ \\
\hline $\begin{array}{l}\text { Biblioteca Pedagógica } \\
\text { Brasileira }\end{array}$ & $\begin{array}{l}\text { Companhia Editora } \\
\text { Nacional/SP }\end{array}$ & $\begin{array}{l}\text { Fernando de Azevedo } \\
\text { João Batista Damasco Penna }\end{array}$ \\
\hline Biblioteca Didática Brasileira & $\begin{array}{l}\text { Gráfica Editora Aurora } \\
\text { Ltda./RJ }\end{array}$ & Afro do Amaral Fontoura \\
\hline $\begin{array}{l}\text { Curso de Psicologia e } \\
\text { Pedagogia }\end{array}$ & $\begin{array}{l}\text { Companhia Editora } \\
\text { Nacional/SP }\end{array}$ & $\begin{array}{l}\text { Theobaldo de Miranda } \\
\text { Santos }\end{array}$ \\
\hline Coleção de Ensino Normal & $\begin{array}{l}\text { Livraria Acadêmica Saraiva } \\
\text { \& Cia./SP }\end{array}$ & Adolfo Packer \\
\hline $\begin{array}{l}\text { Biblioteca do Estudante } \\
\text { Brasileiro }\end{array}$ & Editora A noite/RJ & Jonas Correia \\
\hline Biblioteca Universitária & $\begin{array}{l}\text { Companhia Editora } \\
\text { Nacional/SP }\end{array}$ & Dr. Cruz Costa \\
\hline Biblioteca Universitária & $\begin{array}{l}\text { Livraria Acadêmica Saraiva } \\
\text { \& Cia./SP }\end{array}$ & Não consta \\
\hline $\begin{array}{l}\text { Biblioteca Formação de } \\
\text { Psicólogos }\end{array}$ & Fundo de Cultura/RJ & Antônio Gomes Penna \\
\hline $\begin{array}{l}\text { Biblioteca Fundo Universal } \\
\text { de Cultura }\end{array}$ & Fundo de Cultura/RJ & Mário de Moura \\
\hline Coleção Didática do Brasil & Brasil S.A/SP & Não consta \\
\hline Coleção Studium & $\begin{array}{l}\text { Livraria Acadêmica Saraiva } \\
\text { \& Cia./SP }\end{array}$ & Não consta \\
\hline
\end{tabular}




\begin{tabular}{|l|l|l|}
\hline Coleção de Livros Didáticos & Livraria Francisco Alves/RJ & Não consta \\
\hline $\begin{array}{l}\text { Educaço e Tempo Presente } \\
\text { Pedagogogia }\end{array}$ & Vozes/RJ & Não consta \\
\hline $\begin{array}{l}\text { Biblioteca do Pensamento } \\
\text { Universal }\end{array}$ & $\begin{array}{l}\text { Editora e Encadernadora } \\
\text { Formar Ltda./SP }\end{array}$ & Não consta \\
\hline Coleção Pedagógica & F. Briguiet \& C. a Editores/RJ $^{\text {Edial Andes Ltda./SP }}$ & Paulo Maranhão \\
\hline Escola e Vida & Livraria Agir Editora/RJ & Não consta \\
\hline Família & Livraria Agir Editora/RJ & Não consta \\
\hline $\begin{array}{l}\text { Biblioteca Pedagogia } \\
\text { Universal }\end{array}$ & Livraria Editora Odeon/SP & Não consta \\
\hline $\begin{array}{l}\text { Biblioteca de Filosofia y } \\
\text { Pedagogia }\end{array}$ & $\begin{array}{l}\text { Editorial Poblet/Buenos } \\
\text { Aires }\end{array}$ & Não consta \\
\hline Curso de Pedagogia Cristã & $\begin{array}{l}\text { Editora Coleção F.T.D. } \\
\text { Ltda./SP }\end{array}$ & Não consta \\
\hline $\begin{array}{l}\text { Biblioteca de Formação da } \\
\text { Professora Primária }\end{array}$ & $\begin{array}{l}\text { Editora Nacional de } \\
\text { Direito/RJ }\end{array}$ & Não consta \\
\hline Vida e Educação & $\begin{array}{l}\text { Edição da Livraria do } \\
\text { Globo/RS }\end{array}$ & Álvaro Magalhães \\
\hline Saber Atual & $\begin{array}{l}\text { Difusão Europeia do } \\
\text { Livro/SP }\end{array}$ & Não consta \\
\hline
\end{tabular}

Fonte: Elaborado pelas autoras.

O trabalho, de início, constou da localização das coleções e paralelamente ao levantamento dos títulos das mesmas. Buscou-se então localizar as fichas matrizes, elaboradas pela antiga bibliotecária da escola. Desse trabalho foi possível perceber que as coleções possuíram outros livros além daqueles que haviam sido localizados, mas que se perderam em algum momento da história da instituição. Por outro lado, nem sempre as fichas matrizes foram localizadas, tal como se pode observar no quadro abaixo:

Quadro 2: Coleção de Ensino Normal - EE Carlos Gomes.

\begin{tabular}{|l|l|l|l|}
\hline Título & Autor & $\begin{array}{l}\text { Exemplares } \\
\text { localizados }\end{array}$ & $\begin{array}{l}\text { Fichas } \\
\text { localizadas }\end{array}$ \\
\hline Práticas Escolares (v. 1) & Antônio d'Ávila & Sim & Sim \\
\hline Práticas Escolares (v. 2) & Antônio d'Ávila & Sim & Sim \\
\hline Práticas Escolares (v. 3) & Antônio d'Ávila & Sim & Sim \\
\hline $\begin{array}{l}\text { Sociologia Geral } \\
\text { (Um esquema de) }\end{array}$ & Juvenal Paiva Pereira & Não & Sim \\
\hline História da Educação & Bento de Andrade Filho & Sim & Sim \\
\hline Psicologia Humana & João de Sousa Ferraz & Não & Sim \\
\hline $\begin{array}{l}\text { Biologia Aplicada à acrim } \\
\text { Educação }\end{array}$ & Aristides Ricardo & Sim & Sim \\
\hline $\begin{array}{l}\text { Noções de Psicologia da } \\
\text { Criança }\end{array}$ & João de Sousa Ferraz & Não & Não \\
\hline Compêndio de Psicologia & José Rodrigues de Arruda & Não & Não \\
\hline Flor do Lácio & Cleófano Lopes de Oliveira & Não & Sim \\
\hline
\end{tabular}




\begin{tabular}{|l|l|l|l|}
\hline $\begin{array}{l}\text { História da Civilização } \\
\text { Brasileira }\end{array}$ & Dú́lio Ramos & Não & Não \\
\hline $\begin{array}{l}\text { Noções de Psicologia } \\
\text { Educacional }\end{array}$ & João de Sousa Ferraz & Não & Não \\
\hline
\end{tabular}

Fonte: Elaborado pelas autoras.

Após o levantamento, vem sendo realizada uma nova descrição com uma ficha de descrição bibliográfica, forjada a partir de um código de referência que adere ao já descrito para documentos e outros itens dos diferentes acervos deste arquivo. As figuras abaixo são exemplos das fichas matrizes que foram localizadas no acervo:

Figuras 1 e 2: Exemplo de ficha localizada na Biblioteca da EE Carlos Gomes.

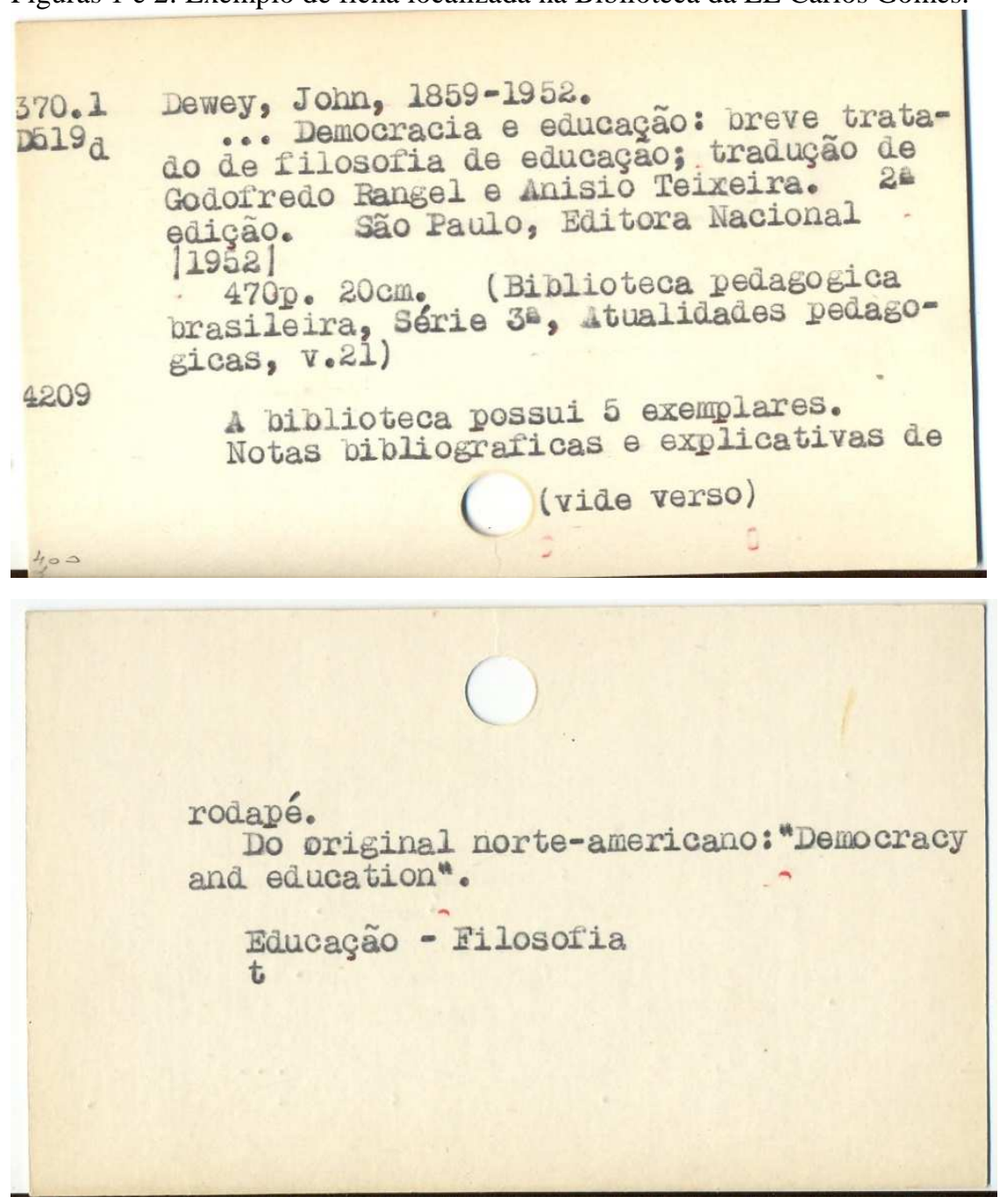

Fonte: Acervo da Biblioteca da EE Carlos Gomes.

Quanto à nova ficha elaborada, esta segue o modelo do quadro abaixo: 
Quadro 3: Nova ficha de catalogação bibliográfica - EE Carlos Gomes.

FUNDO: Escola Estadual "Carlos Gomes" (EE "Carlos Gomes" - Campinas/SP/BR)

GRUPO: EEPSG "Carlos Gomes"

SUBGRUPO: Manual Escolar

\begin{tabular}{l|l|l}
$\begin{array}{l}\text { Código } \\
\text { de } \\
\text { Referênci } \\
\text { a: }\end{array}$ & BR SP EE Carlos Gomes/ Campinas & Cota: \\
\hline
\end{tabular}

TÍTULO: Democracia e Educação

$\operatorname{AUTOR}(E S): D E W E Y$, John

(IDing

\begin{tabular}{|l|l|l|l|l|}
\hline \multicolumn{2}{|l|}{ IDIOMA: Português } & \multicolumn{2}{l}{$\begin{array}{l}\text { Idioma Original: Inglês } \\
\text { Tradutor: RANGEL, Godofredo }\end{array}$} \\
\hline $\begin{array}{l}\text { DATA DE PUBLICAÇÃO: } \\
1952\end{array}$ & $\begin{array}{l}\text { EDIÇÃO: } \\
2^{\circ}\end{array}$ & \multicolumn{2}{l|}{ EDITORA: Companhia Editora Nacional } \\
\hline $\begin{array}{l}\text { COLEÇÃO: Biblioteca Pedagógica } \\
\text { Brasileira }\end{array}$ & $\begin{array}{l}\text { SÉRIE: } 3^{\circ}, \text { Atualidades } \\
\text { Pedagógicas }\end{array}$ & $\begin{array}{l}\text { VOLUME: } \\
21\end{array}$ & $\begin{array}{l}\mathrm{N}^{\circ} \\
\text { EXEMPLARES: } \\
2\end{array}$
\end{tabular}

\begin{tabular}{|l|l|}
\hline LOCAL: São Paulo & ISBN: \\
\hline
\end{tabular}

GÊNERO: Manual Escolar $\quad$ USO: Escola Normal

DISCIPLINA: Filosofia da Educação, Assunto: Educação como necessidade de vida, a

História da Educação.

educação como função social, a educação como direção, a educação como crescimento, objetivos da educação, a natureza da matéria de estudo, estudos intelectuais e estudos práticos e teoria de moral.

CARIMBOS: EEPSG "Carlos Gomes".

CARIMBO DE TOMBO: Sim - Registro n.4209

FICHA DE EMPRÉSTIMO: Sim, treze empréstimos de 1957 a 1968.

CARACTERISTIICAS E ESTADO DA OBRA: Capa brochura faltante, costura de caderno, lombada rasgada, folhas manchadas.

MARCAS DE LEITURA: Não

MARCAS DE POSSE: Não RELÍQUIAS: Sim, um poema em folha separada.

NOTA: Prefácio de Anísio Teixeira

Preenchimento da Ficha: Gustavo M. Costa e João Vitor $\quad$ DATA: 01/07/2015

Fonte: Elaborada pelos bolsistas PIBIC-EM/UNICAMP, orientados pela Profa. Dra. Maria Cristina Menezes.

Rev. Iberoam. Patrim. Histórico-Educativo, Campinas (SP), v. 1, n. 1, p. 172-181, jul./dez. 2015 
Por constituírem-se em itens de um mesmo fundo arquivístico, traz as marcas que os identificam ao fundo e ao mesmo tempo às particularidades da descrição de um item bibliográfico.

\section{ALGUMAS CONSIDERAÇÕES}

O levantamento das coleções pedagógicas da biblioteca da Escola Normal de Campinas possibilita conhecer a organização que receberam da antiga bibliotecária da escola, com o aporte de: carimbos, classificação e número de registro. Nesse sentido, os livros possuem ficha de registro de empréstimo, com datas de retirada e devolução pelos usuários que os consultavam - que podem dar alguma pista sobre a demanda, se significativa (ou não) de empréstimos e quais os títulos mais procurados.

Outrossim, é possível realizar uma análise das "marcas de leitura" (CUNHA, 2012) muitas vezes deixadas nos livros por aqueles que os emprestavam, com a possibilidade de se compreender como se deu a circulação dessas coleções entre professores da instituição e alunos do curso normal e o uso provável que delas fizeram.

As fichas matrizes dos livros, por sua vez, trazem informações por meio das quais se enuncia quantos exemplares havia de cada livro, se as coleções estavam completas ou se constavam somente dos exemplares localizados.

Por fim, o levantamento e o estudo das coleções pedagógicas possibilitam identificar quais saberes pedagógicos foram divulgados por meio dos impressos, bem como conhecer os grupos que se envolveram nos embates relativos a questões educacionais, buscando ampliar a visão do campo educacional em conformação no período delimitado para esse estudo (19301960).

\section{REFERÊNCIAS}

BICCAS, Maurilane de Souza; CARVALHO, Marta Maria Chagas de. Reforma escolar e práticas de leitura de professores: a Revista do Ensino. In: CARVALHO, Marta Maria Chagas de; VIDAL, Diana Gonçalves (orgs.). Biblioteca e formação docente: percursos de leitura (1902-1935). Belo Horizonte: Autêntica, 2000, p. 63-91.

CATANI, Denice Barbara; SOUSA, Cynthia Pereira de. A geração de instrumentos de pesquisa em História da Educação: estudos sobre revistas de ensino. In: VIDAL, Diana Gonçalves; HILSDORF, Maria Lúcia Spedo. (orgs.). Brasil 500 anos: tópicas em História da Educação. São Paulo: Editora da Universidade de São Paulo, 2001, p. 241-254. 
CERTEAU, Michel de. A invenção do cotidiano: artes de fazer. Trad. Ephraim Ferreira Alves. Apresentação Luce Giard. 2. ed. Petrópolis, RJ: Vozes, 1996, 351p.

CHARTIER, Roger. A história cultural: entre práticas e representações. Trad. Maria Manuela Galhardo. Rio de Janeiro: Bertrand Brasil; Lisboa: Difel, 1990, 239p.

A ordem dos livros: leitores, autores e bibliotecas na Europa entre os séculos XIV e XVIII. Trad. Mary Del Priori. Brasília: UnB, 1999, 111p.

CUNHA, Maria Teresa Santos. Rastros de leituras: um estudo no acervo de livros do Museu da Escola Catarinense (décadas de 20 a 60 do século XX). Educação, Porto Alegre, v. 35, n. 1, p. 18-27, jan./abr. 2012.

FERNANDES, Rogério. Escola Normal de Campinas. In: MENEZES, Maria Cristina (ccord.). Inventário Histórico Documental: Escola Normal de Campinas (1903-1976) - De Escola complementar a Instituto de Educação. Campinas, SP: FE/Unicamp, 2009, p. 01-04.

MENEZES, Maria Cristina. O mapeamento de uma biblioteca de formação de professores. In: Anais do VI Congresso Brasileiro de História da Educação, SBHE/UFES, Vitória/ES, 2011, 13p. 